\title{
Sistemas de cultivo e propriedades químicas de um latossolo em área de agricultura familiar na Amazônia
}

Os sistemas de cultivo mais conhecidos são: o sistema de cultivo tradicional, muito utilizados por agricultores familiares e o sistema de cultivo mais intensivo, que utiliza os monocultivos. Ambos apresentam características diferentes, com vantagens e desvantagens. Como uma alternativa para os pequenos produtores, temos os sistemas agroflorestais, que consistem em um busca por lucratividade juntamente com um uso sustentável da terra. Dependendo do sistema a ser adotado nos cultivos poderá ser observado característica diferentes nos solos em que esses sistemas serão implantados. Logo, o trabalho teve como objetivo avaliar os atributos químicos de solos sob diferentes sistemas de uso da terra, no município de São Francisco do Pará, com o propósito de caracterizá-los quimicamente. A coleta de solos foi realizada em dezembro de 2006, em 7 (sete) áreas amostrais, sendo: três sistemas agroflorestais - SAF1 (pomar de coqueiro e cultivos agrícolas como, melancia e mandioca); SAF 2 (pomar de coqueiros, cupuaçuzeiros e cajueiros); SAF3 (composto por seringueiras, gravioleiras e cupuaçuzeiros). Dois cultivos coqueiro e cultivos agrícolas como, melancia e mandioca); SAF 2 (pomar de coqueiros, cupuaçuzeiros e cajueiros); SAF3 (composto por seringueiras, gravioleiras e cupuaçuzeiros). Dois cultivos mandioca, sem adubação e Floresta Secundária - aproximadamente 20 anos de idade. Os valores do pH do solo variaram de 4,3 a 5,4. Os teores de $\mathrm{P}$ variaram de baixo (1,5 mg dm-3) há muito alto (43,10 mg dm-3). O valor médio da concentração de carbono orgânico foi maior para a Floresta Secundária com $11,78 \mathrm{~g} / \mathrm{Kg}$ e menor para o SAF $1 \mathrm{com} 6,45 \mathrm{~g} / \mathrm{Kg}$. 0 menor valor de concentração de matéria orgânica foi registrado no SAF 1 com 11,11 g/Kg e o maior na Floresta Secundária (FS) com 20,10 g/Kg. Os valores para o magnésio variaram de 0,28 cmolc dm-3 no SAF 3 a $0,47 \mathrm{cmolc} \mathrm{dm}-3$ na floresta secundária. Os valores de concentrações foram 'baixos' para o potássio e 'médios' para o cálcio. Logo, os valores de atributos químicos encontrados nos solos analisados estão caracterizados com nível de nutrientes médios e acidez elevada. Possivelmente em áreas com valores superiores, são devidos o sistema de queima e o fornecimento de adubações. Outro ponto importante pode ser observado no baixo nível tecnológico aplicado nos SAF's.

Palavras-chave: Fertilidade do solo; Sistemas agroflorestais; Agricultura familiar.

\section{Chemical properties of soils under different cultivation systems in the Amazon}

\begin{abstract}
The most well known farming systems are: the traditional farming system, widely used by family farmers and the more intensive farming system, which uses monocultures. Both have differen The most well known farming systems are. the traditional farming system, widely used by family farmers and the more intensive farming system, which uses monocultures. Both have different land use. Depending on the system to adve antages. As an alternative for small producers, we have agroforestry systems, which consist of a search for profitability together with sustainable land use. Depending on the system to be adopted in the crops, different characteristics may be observed in the soils in which these systems will be implanted. Therefore, the present work aimed to evaluate the chemical attributes of soils under different land use systems, in the municipality of São Francisco do Pará, with the purpose of characterizing them chemically. Soil
collection was carried out in December 2006, in 7 (seven) sample areas, as follows: three agroforestry systems - SAF1 (coconut orchard and agricultural crops such as watermelon and manioc); collection was carried out in December 2006, in 7 (seven) sample areas, as follows: three agroforestry systems - SAF1 (coconut orchard and agricultural crops such as watermelon and manioc),
SAF 2 (coconut orchard, cupuaçuzeiros and cashew trees); SAF 3 (composed of rubber trees, soursop and cupuaçuzeiros). Two annual crops: Roça 1 (planting cassava by cutting and burning without fertilization system (2006); Roça 2 (planting corn and manioc fertilized (2006); Pasture planted in old cultivation of cassava, without fertilization and Secondary Forest - approximately 20 years of age. The soil pH values ranged from 4.3 (SAF 3) to 5.4, characterizing acidic to very acidic soils. $1.5 \mathrm{mg} \mathrm{dm}-3$ ) to very high ( $43.10 \mathrm{mg} \mathrm{dm}-3)$. The very high value is probably related to the residual effect, as the SAF 3 is found in an old rubber plantation that received periodic fertilizations. average value of organic carbon concentration was higher for Secondary Forest with $11.78 \mathrm{~g} / \mathrm{kg}$ and lower for SAF 1 with $6.45 \mathrm{~g} / \mathrm{kg}$. The lowest organic matter concentration value was registered in SAF 1 with $11,11 \mathrm{~g} / \mathrm{kg}$ and the highest in the Secondary Forest (FS) with calcium. Therefore, the values of chemical attributes found in the analyzed soils are characterized by medium nutrient levels and high acidity. Possibly in areas with higher values, the burning system and the supply of fertilizers are due. Another important point can be seen in the low technological level applied to SAF's.
\end{abstract}

Keywords: Soil fertility; Agroforestry systems; Smallholding.

Topic: Química Agrícola e Ambiental

Reviewed anonymously in the process of blind peer.
Received: 03/07/2021

Approved: 28/07/2021
Paulo Cesar Silva Vasconcelos (iD)

Universidade Federal Rural da Amazônia, Brasil

http://lattes.cnpq.br/4922451892117153

http://orcid.org/0000-0003-2236-2857

pcsvasc@gmail.com

Jessivaldo Rodrigues Galvão (iD

Universidade Federal Rural da Amazônia, Brasil

http://lattes.cnpq.br/0013591065769741

http://orcid.org/0000-0003-4242-6555

jessigalvao50@gmail.com

\section{Thiago Costa Viana (it)}

Universidade Federal Rural da Amazônia, Brasil

http://lattes.cnpq.br/2173828234634124

http://orcid.org/0000-0002-6688-676X

thiagocostaaa19@gmail.com
Mauro Junior Borges Pacheco

Universidade Federal Rural da Amazônia, Brasi

http://lattes.cnpq.br/0756046215703468

http://orcid.org/0000-0001-6024-7054

mauro.jr720@gmail.com

João da Luz Freitas (DD

Universidade Federal Rural da Amazônia, Brasil

http://lattes.cnpq.br/7708025882561023

http://orcid.org/0000-0002-9751-9479

ifreitas.ap@gmail.com
Referencing this:

VASCONCELOS, P. C. S.; GALVÃO, J. R.; VIANA, T. C.; PACHECO, M. J. B.; FREITAS, J. L.. Sistemas de cultivo e propriedades químicas de um latossolo em área de agricultura familiar na Amazônia. Revista Ibero Americana de Ciências Ambientais, v.12, n.7, p.125-134, 2021. DOI: http://doi.org/10.6008/CBPC2179-6858.2021.007.0012 


\section{INTRODUÇÃO}

A agricultura familiar na Amazônia é constituída a partir das unidades familiares, em que se observa o funcionamento da produção agrícola no âmbito familiar, relacionados principalmente com as questões agroambientais e o desenvolvimento sustentável, no qual se aplica um sistema de cultivo mais rustico, conhecido com derruba e queima, sendo repassado a cada geração. Logo, a dinâmica da propriedade e as relações com os fatores sociais e tecnológicos devem estar associados as condições produtivas dos agricultores.

O sistema de cultivo intensivo, baseado principalmente na exploração de monocultivos, tem contribuído para a degradação do meio ambiente, dando origem a ecossistemas pouco estáveis além de provocar desequilíbrio socioeconômico da população rural (LEITE et al., 2002).

Os sistemas agroflorestais (SAF) são uma das alternativas ao tradicional sistema de derruba e queima praticado pelos pequenos agricultores de todo o mundo. Apesar de ser considerada uma prática de uso da terra de longa tradição, seu estudo como ciência é relativamente recente, principalmente na região amazônica.

O estudo dos SAF produtivos torna-se de suma importância pela inclusão de uma nova variável a ser entendida, ou seja, a interação/relação que ocorre entre os cultivos agrícolas e as árvores presentes nos sistemas agroflorestais (SALGADO et al., 2006).

O uso intenso das terras exploradas com culturas perenes ressalta a necessidade de se manter uma exploração racional, a fim de preservar o potencial produtivo dos solos; desta forma, o conhecimento das propriedades químicas e físicas do solo é uma ferramenta fundamental para direcionar práticas que reduzam o depauperamento a níveis toleráveis (THEODORO, 2001).

Para que haja uma melhor utilização destes solos, sabendo principalmente da baixa fertilidade dos solos amazônicos, sobretudo pelos agricultores familiares, é necessário que se conheça a dinâmica de suas propriedades químicas, permitindo, uma intervenção racional deste importante recurso natural, possibilitando sua sustentabilidade, bem como a recuperação de áreas alteradas e exauridas pelo uso inadequado (SENA, 2006).

Portanto, o objetivo do trabalho foi avaliar os atributos químicos de solos sob diferentes sistemas de uso em unidades de produção de agricultores familiares do município de São Francisco do Pará, com a caracterização da fertilidade destes solos.

\section{MATERIAIS E MÉTODOS}

O experimento foi conduzido na área dos produtores rurais, localizada na mesorregião do nordeste paraense no município de São Francisco do Pará, no ano de 2006. O tipo climático da área de estudo é classificado como Am, segundo Koppen, com as seguintes características: precipitação anual entre 1750 a $3000 \mathrm{~mm}$; média da temperatura do mês mais frio superior a $18^{\circ} \mathrm{C}$.

As amostras de solo foram coletadas através de metodologia aplicada pelo IAPAR (1996), onde é 
preconizado que, se a área for heterogênea é necessário dividi-la aplicando a mesma intensidade amostral para cada área. No caso da área de estudo, o terreno é plano, sem formas topográficas expressivas (IDESP, 1995) e o solo é classificado como Latossolo Amarelo (IDESP, 1993).

Para a avaliação das propriedades químicas dos solos foram selecionadas sete áreas amostrais, sendo 03 (três) sistemas agroflorestais (SAF), 02 (dois) cultivos anuais (roçados), uma pastagem e uma floresta secundária com aproximadamente 20 anos. Os roçados foram selecionados em áreas próximas, não contíguas aos SAF. As coletas foram realizadas no mês de dezembro, período de menor pluviosidade no município. Foram coletadas quatro amostras compostas na camada de 0 a $20 \mathrm{~cm}$, de cada área amostral selecionada. Cada amostra composta foi obtida de 20 amostras simples. As amostras simples foram posteriormente homogeneizadas em balde plástico de onde retirou-se uma quantidade de aproximadamente $300 \mathrm{~g}$, acondicionada em saco plástico que, contendo etiqueta de identificação da amostra para análises laboratoriais.

O histórico de cada área amostrada foi registrado a partir do ano de 2001, relatando-se os cultivos, adubação caso tenha sido realizada, práticas culturais e outras características que possam provocar mudanças nos teores de nutrientes. As características das áreas amostrais estão resumidas na tabela 1.

Tabela 1: Resumo das atividades realizadas anualmente (2001 - 2006) nos solos sob diferentes sistemas de uso da terra por agricultores familiares no Município de São Francisco do Pará-PA.

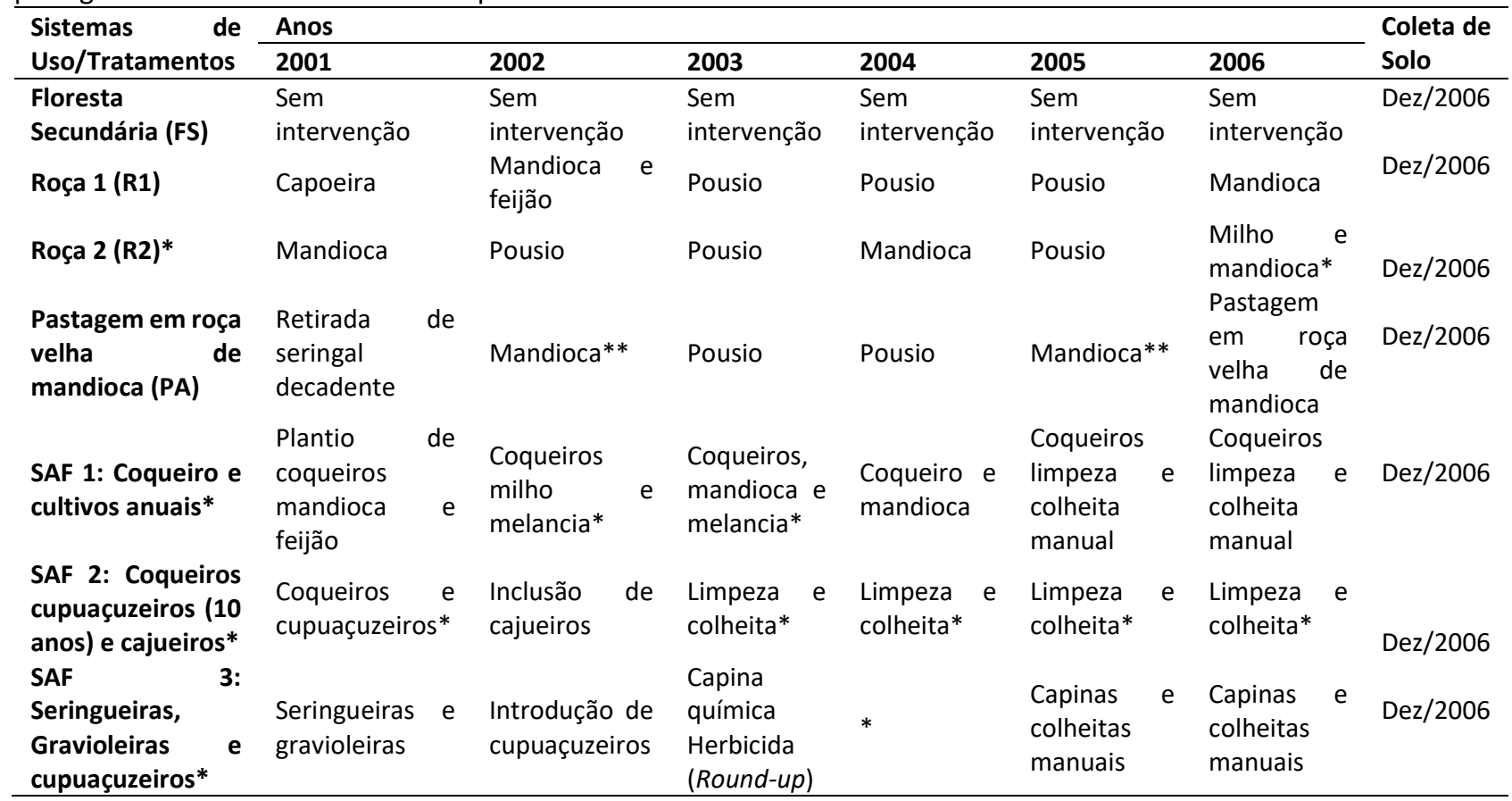

Obs.: * Adubados; ${ }^{* *}$ Corte e queima.

As análises químicas foram realizadas no Laboratório de Análises Químicas de Solos, do Instituto de Ciências Agrárias da Universidade Federal Rural da Amazônia, seguindo a metodologia da Embrapa (1997).

Os dados obtidos das variáveis estudadas foram submetidos à análise de variância. As médias dos tratamentos foram comparadas por meio do teste de Duncan, a 1\% de significância. As análises estatísticas foram realizadas utilizando-se o software Statistical Analysis System (SAS). 


\section{RESULTADOS E DISCUSSÃO}

Os valores apresentados na Tabela 2 referem-se às médias correspondentes às variáveis químicas analisadas de solos das propriedades rurais de agricultores familiares no município de São Francisco do Pará, submetidos aos tratamentos estudados.

Tabela 2: Resumo da análise de variância para as variáveis químicas de solos nas unidades de produção de agricultores familiares do município de São Francisco do Pará, sob diferentes sistemas de uso da terra (SUT). Onde: T1 = Floresta secundária; $\mathrm{T} 2=$ Roça $1 ; \mathrm{T} 3=$ Roça $2 ; \mathrm{T} 4$ = Pastagem; T5 = SAF 1; T6 = SAF 2; T7 = SAF 3.

\begin{tabular}{|c|c|c|c|c|c|c|c|c|}
\hline SUT & $\mathbf{P}$ & $\mathrm{K}$ & $\mathrm{Ca}$ & $\mathrm{Mg}$ & $\mathrm{H}+\mathrm{Al}$ & M.O & C. 0 & $\mathrm{pH}_{\mathrm{H} 2 \mathrm{O}}$ \\
\hline & \multicolumn{2}{|c|}{ - } & \multicolumn{2}{|c|}{ - } & \multicolumn{2}{|c|}{-------------g kg-1.-------- } & & \\
\hline T1 & $1,50 \mathrm{C}$ & $0,018 \mathrm{~B}$ & $4,55 \mathrm{~B}$ & $0,47 \mathrm{~A}$ & $0,61 \mathrm{C}$ & $20,10 \mathrm{~A}$ & $11,78 \mathrm{~A}$ & $4,95 \mathrm{CD}$ \\
\hline T2 & $2,43 \mathrm{C}$ & $0,083 \mathrm{~A}$ & $4,34 \mathrm{~B}$ & $0,35 \mathrm{~A}$ & $0,49 \mathrm{D}$ & $18,25 \mathrm{~A}$ & $10,70 \mathrm{~A}$ & $5,30 \mathrm{AB}$ \\
\hline T3 & $6,65 \mathrm{BC}$ & $0,068 \mathrm{~A}$ & $3,73 \mathrm{CD}$ & $0,42 \mathrm{~A}$ & $0,23 \mathrm{~F}$ & $18,06 \mathrm{~A}$ & $10,48 \mathrm{~A}$ & $5,40 \mathrm{~A}$ \\
\hline T4 & $5,73 \mathrm{BC}$ & $0,015 \mathrm{~B}$ & $4,57 \mathrm{~B}$ & $0,46 \mathrm{~A}$ & $0,76 \mathrm{~B}$ & $12,83 \mathrm{BC}$ & $7,44 \mathrm{BC}$ & $4,93 \mathrm{CD}$ \\
\hline T5 & $2,10 \mathrm{C}$ & $0,028 \mathrm{~B}$ & $3,38 \mathrm{D}$ & $0,32 \mathrm{~A}$ & $0,36 \mathrm{E}$ & $11,11 \mathrm{C}$ & $6,45 \mathrm{C}$ & $5,13 \mathrm{BC}$ \\
\hline T6 & $12,78 \mathrm{~B}$ & $0,010 \mathrm{~B}$ & $4,19 \mathrm{BC}$ & $0,38 \mathrm{~A}$ & $0,53 \mathrm{CD}$ & $13,35 \mathrm{BC}$ & $7,75 \mathrm{BC}$ & $4,85 \mathrm{D}$ \\
\hline T7 & $43,10 \mathrm{~A}$ & $0,015 \mathrm{~B}$ & $5,65 \mathrm{~A}$ & $0,28 \mathrm{~A}$ & $1,16^{\mathrm{a}}$ & $14,35 \mathrm{~B}$ & $8,33 \mathrm{~B}$ & $4,30 \mathrm{E}$ \\
\hline Médias & 10,61 & 0,03 & 4,34 & 0,38 & 0,59 & 15,44 & 8,99 & 4,98 \\
\hline
\end{tabular}

Obs.: Médias seguidas pelas mesmas letras dentro da mesma coluna não diferem entre si pelo teste de Duncan a 0,01 de probabilidade.

Nos resultados obtidos para pH em água (Tabela 2 ) verifica-se um menor valor para o SAF3 com 4,3 e o maior valor para o R2 com 5,4. Segundo Raij et al. (1996) e Osaki (1991), valores abaixo de 4,5 são considerados de elevada acidez, onde possivelmente a matéria orgânica possa estar contribuindo para a redução do pH através da síntese dos compostos orgânicos que ao reagirem na solução do solo, liberam íons $\mathrm{H}^{+}$. Da mesma forma, segundo Malavolta (1980), a decomposição da matéria orgânica no solo também provoca aumento na acidez, pois no processo há liberação de amônia que sofre nitrificação.

Os resultados de pH em água em Latossolo Amarelo obtidos nos estudos de Ferreira (2004) no município de Castanhal-PA, ao comparar o efeito da profundidade do solo em sistemas agroflorestais, variaram de 3,4 a 3,8. Sena (2006) registrou valores médios para pH em água, com variação entre 3,88 (cacau+açaí - período chuvoso) e 4,36 (pupunheira - período seco) em função de diferentes sistemas de uso do solo.

Em solos no Município de Aurora do Pará-PA, Rodrigues (2006) ao analisar quimicamente solos de $\mathrm{SAF}$, capoeira e pastagem, registrou valores de $\mathrm{pH}$ variando de 4,3 (capoeira) no período seco a 5,5 (pastagem e SAF com neen - Azadirachta indica) no período chuvoso. Comparando com os resultados deste estudo, o menor e o maior valor encontrados também foram para floresta secundária e SAF, respectivamente. Solos de florestas tendem ser mais ácidos que os de pastagem; as culturas podem variar muito nas quantidades de Ca e Mg que são absorvidos e removidos do solo, as leguminosas geralmente retiram estes nutrientes em maiores proporções que as gramíneas (MALAVOLTA, 1980).

Estes valores de elevada acidez em Latossolos Amarelos são considerados aceitáveis em decorrência do material de origem e da intensa ocorrência de chuvas na região Amazônica, pois a água que atravessa o solo pode levar elementos "básicos" $\operatorname{com~K}, \mathrm{Ca}^{+2}$, e $\mathrm{Mg}^{+2}$ que são substituídos por elementos "ácidos" como $\mathrm{H}^{+}, \mathrm{Al}^{+3} \mathrm{e} \mathrm{Mn}^{+2}$ (MALAVOLTA, 1980), portanto estes resultados corroboram a maioria dos trabalhos realizados na região quanto ao $\mathrm{pH}$ em solo. 
Vale ressaltar que o discreto aumento de $\mathrm{pH}$ em Roça 1 e Roça 2, pode ter sido atribuído à queima recente e a adubação química, respectivamente, apresentando, desta forma, diferença significativa em relação aos outros tratamentos para esta variável.

Com relação ao elevado teor de acidez registrado nas áreas sob sistemas agroflorestais, recomendase que estas recebam correções de acordo com as necessidades de cada tratamento. Os valores médios para as concentrações de Alumínio foram menores para Roça 2 com $0,23 \mathrm{cmol}_{c} \mathrm{dm}^{-3}$ e o maior foi para o SAF 3 com $1,16 \mathrm{cmol}_{c} \mathrm{dm}^{-3}$. Sena (2006) encontrou valores variando de $1,41 \mathrm{cmol}_{c} / \mathrm{dm}^{3}(0-5 \mathrm{~cm})$ a $1,69 \mathrm{cmol}_{c} / \mathrm{dm}^{3}$ $(10-20 \mathrm{~cm})$ no período chuvoso, e de 1,08 a $1,25 \mathrm{cmol}_{\mathrm{c}} / \mathrm{dm}^{3}$, nas mesmas profundidades. Estes valores de alumínio trocável são classificados como nível alto, de acordo com Raij et al. (1996), podendo causar toxidez às plantas.

As concentrações médias de alumínio em solos com SAF, capoeira e pastagem, encontradas por Rodrigues (2006) variaram de $0,19 \mathrm{cmol}_{c} / \mathrm{dm}^{3}$ a $1,04 \mathrm{cmol}_{c} / \mathrm{dm}^{3}$ no período seco e de $0,10 \mathrm{cmol}_{c} / \mathrm{dm}^{3}$ a 0,36 $\mathrm{cmol}_{\mathrm{c}} / \mathrm{dm}^{3}$ no período chuvoso. Os resultados obtidos para os teores de alumínio por esta autora são considerados de nível "baixo", corroborando, em parte, com os valores apresentados neste estudo. Após um levantamento de reconhecimento de baixa intensidade dos solos da região de inserção do Projeto RECA (Reflorestamento Econômico Consorciado e Adensado) nos Estados de Rondônia, Acre e Amazonas, Amaral et. al. (2000) verificaram teores de alumínio trocável variando de 3,0 a 6,0 $\mathrm{cmol}_{\mathrm{c}} / \mathrm{Kg}$, predominando, na maioria desses solos, valores superiores a $4,5 \mathrm{cmol} / \mathrm{Kg}$, os quais condicionados pela baixa soma de bases trocáveis, condicionam uma alta saturação de alumínio, enquadrando o perfil descrito com caráter alumínico, no qual os autores sugerem a necessidade de aplicação de corretivos (calagem) nestes solos para eliminação da toxicidade desse elemento nas plantas cultivadas, assim como elevar a concentração de cálcio e magnésio.

Perez et al. (2004) encontrou valores de nível "médio" e "baixo" para a concentração de alumínio ao comparar as características químicas do solo em sistema sob manejo agroflorestal e manejo convencional na Zona da Mata-MG. O cultivo consorciado favorece a manutenção do pH e a redução da saturação por alumínio, devido ao aumento do teor de matéria orgânica, muito embora as necessidades de nutrientes dos componentes do consórcio devam ser satisfeitas por meio de entradas externas, para evitar o empobrecimento gradual do solo (NEVES et al., 2007).

A concentração de fósforo nos solos das unidades amostrais foi quantificada nos diferentes tratamentos estudados. Os tratamentos apresentaram diferença entre si para esta variável. 0 tratamento SAF 3 foi o que apresentou a maior concentração do nutriente, com diferença significativa comparado aos demais tratamentos $\left(43,10 \mathrm{mg} \mathrm{dm}^{-3}\right)$. O menor valor encontrado foi para a Floresta Secundária (FS) de 1,5 $m g d m^{-3}$.

O teor de fósforo encontrado no solo pode ser originado da rocha mãe que contém minerais primários como apatita e seus derivados, ou da matéria orgânica, oriundo de componentes de detritos vegetais, bem como de organismos mortos. Cerca de 95 a $99 \%$ dos fosfatos estão presentes no solo de forma não assimilável pelas plantas (insolúveis) e a indisponibilidade deste elemento pode ser considerado um fator limitante para o crescimento das plantas. O fósforo é absorvido pelas raízes principalmente como íon 
ortofosfato $\left(\mathrm{H}_{2} \mathrm{PO}_{4}{ }_{4}\right)$. O fósforo é importante na formação do ATP (trifosfato de adenosina) que é a principal fonte energética da planta. Energia utilizada no transporte de assimilados, no armazenamento e transferência de energia, na divisão celular, no aumento das células e na transferência de informações genéticas (SENGIK, 2005).

Os valores de P encontrados por Sena (2006), ao analisar diferentes sistemas de uso em diferentes épocas de amostragem no Município de Marituba-PA, variaram de 2,28 $\mathrm{mg} \mathrm{dm}^{-3}$ em floresta secundária a $7,15 \mathrm{mg} \mathrm{dm}^{-3}$ em SAF com cacau + açaí.

Rodrigues (2006) ao realizar análise físico-química de solo de SAF e áreas de capoeira e pastagem no município de Aurora do Pará-PA, obteve valores de fósforo variando de $0,81 \mathrm{mg} \mathrm{dm}^{-3}$ (pastagem) no período seco a 4,61 mg dm${ }^{-3}$ (Swietenia macrophylla - mogno + Azadirachta indica - neen) no período chuvoso.

Salgado et al. (2006) encontraram valores mais elevados ao avaliar a fertilidade de solos em sistemas agroflorestais com cafeeiros em Minas Gerais (média geral de 21,74 mg dm $\mathrm{dm}^{-3}$ ), considerando que os maiores valores de matéria orgânica e pH nos sistemas estudados possa ter afetado diretamente a disponibilidade de fósforo. Segundo Fernandes et al. (1997), ocorre maior quantidade de fósforo nas camadas superficiais do solo, correlacionado com maior teor de matéria orgânica.

A fonte natural de fósforo no solo é a matéria orgânica, ou outro resíduo orgânico que possa ser adicionado ao solo, como estercos e restos de culturas. O fósforo é um nutriente de baixa mobilidade no solo, devendo ser aplicado ao solo o mais próximo das raízes (SENGIK, 2005). A pobreza em fósforo dos solos brasileiros e o seu alto poder de adsorção/fixação fazem com que os adubos fosfatados sejam os mais consumidos no país, embora as necessidades das culturas sejam relativamente baixas (MALAVOLTA, 1980). O SAF 3 pode ter apresentado o valor altíssimo para fósforo pelo fato deste SAF estar em um seringal antigo que recebia adubações químicas frequentes.

Com relação aos teores médios de carbono orgânico, a maior média foi registrada para a Floresta Secundária com 11,78 g/Kg e a menor para o SAF1 com 6,45 g/Kg. Franco et al. (2002) ao quantificar a perda de carbono orgânico, matéria orgânica e nutrientes por processos erosivos comparando solos sob sistemas agroflorestais e solos sob sistemas convencionais, verificaram que o carbono orgânico apresentou valores de perda bastante significativos, principalmente para os sistemas convencionais. Este fato reforça a ideia de que o horizonte superficial dos solos, onde fica a camada mais fértil pelo maior conteúdo de matéria orgânica, fica empobrecida e degradada ao longo dos anos, devido aos processos erosivos, assim, é importante ressaltar que as perdas totais de solo, carbono orgânico e nutrientes é significativamente menor em sistemas agroflorestais quando comparado à sistemas convencionais, o que indica a maior sustentabilidade ecológica destes e comprova que eles são capazes de conservar os recursos naturais, evidenciando a importância da conversão dos sistemas convencionais em sistemas ecologicamente sustentáveis.

O componente arbóreo de um sistema agroflorestal pode ser o maior responsável pela entrada de matéria orgânica no solo causada pela queda de seus elementos vegetais e pela maior dinâmica no processo de ciclagem de nutrientes, o que evita que estes sejam perdidos mais rapidamente, como ocorre em solos descobertos ou com pouca vegetação (pastagens, por exemplo). Desta forma, o maior valor encontrado no 
FS, que é caracterizado por uma floresta secundária, pode ser justificado pelo maior acúmulo de liteira na camada mais superficial do solo.

Quando analisados os solos sob diferentes sistemas de uso da terra, Sena (2006) verificou maior teor de carbono orgânico de 13,05 g/Kg (cacau + açaí) e menor de 10,47 g/Kg (floresta secundária), valores considerados de nível médio.

Os resultados obtidos por Perez et al. (2004) também apontaram maiores teores de carbono orgânico em solos com sistemas agroflorestais com café do que em sistemas convencionais de uso da terra no Sudeste brasileiro, com valores variando de $17,65 \mathrm{~g} / \mathrm{Kg}(15-30 \mathrm{~cm})$ a $30,24 \mathrm{~g} / \mathrm{Kg}(0-5 \mathrm{~cm})$, reforçando a afirmativa de que a camada mais superficial do solo apresenta maior teor de matéria orgânica e consequentemente maior concentração de carbono orgânico.

Os teores de matéria orgânica seguem um padrão diretamente proporcional aos valores obtidos para os teores de carbono orgânico encontrados. O menor valor foi registrado no SAF1 com 11,11 g. kg-1 e o maior na Floresta Secundária com 20,10 g. $\mathrm{kg}^{-1}$. A Pastagem, o SAF1 e o SAF2 apresentaram valores considerados baixos de matéria orgânica, bem como para o carbono orgânico. Rodrigues (2006) trabalhando em sistemas agroflorestais, capoeira e pastagem no Município de Aurora do Pará-PA, encontrou valores médios de matéria orgânica entre $12,41 \mathrm{~g} / \mathrm{Kg}$ (cedro) e 20,02 g/Kg (mogno + neen), no período seco. Já no período chuvoso, a autora encontrou os menores valores de 8,61 g/Kg (mogno + cedro) e o maior 15,53 g/Kg (mogno + neen). Para ambos os períodos, foram estudadas profundidades de solo de $0-20 \mathrm{~cm}$, mesma amplitude de coleta utilizada para este estudo.

Ao estudar o efeito da Gliricidia sepium sobre nutrientes do solo em sistemas agroflorestais com milho no agreste paraibano, Marim et al. (2006) verificaram altos teores de matéria orgânica devido a elevada deposição de folhedos nos pontos de amostragem. Analisando os valores em função da sazonalidade, ao final da seca (janeiro), a concentração de matéria orgânica quantificada na superfície do solo foi 73, 43 e 36 maior do que nas épocas da estação chuvosa (abril), final da estação chuvosa (julho) e plena seca (outubro), respectivamente, sustentando a ideia de que sua quantidade e composição no solo apresentam variabilidade espacial e sazonal em relação a outras frações de matéria orgânica do solo, o que mostra ser um bom indicador capaz de detectar mudanças no manejo da cobertura vegetal no sistema estudado pelos autores.

Os valores médios da concentração de magnésio não apresentaram diferença significativa ao serem comparados entre os tratamentos, apresentado valores considerados baixos/médios para este nutriente, variando de $0,28 \mathrm{cmo}_{c} \cdot \mathrm{dm}^{-3}$ no SAF3 a 0,47 $\mathrm{cmo}_{c} \cdot \mathrm{dm}^{-3}$ na Floresta Secundária.

O teor de magnésio trocável que pode ser considerado como médio é de 0,4 a $0,8 \mathrm{cmol}_{c} \mathrm{dm}^{-3}$ de solo. Salgado et al. (2006) ao avaliarem a fertilidade dos solos em sistemas agroflorestais com cafeeiro no Sudeste brasileiro, verificaram que os resultados obtidos apresentaram nível "bom" $\left(0,91 \mathrm{a} 1,5 \mathrm{cmol} \mathrm{dm}^{-3}\right)$ para os cultivos a pleno sol e "médio" $\left(0,46\right.$ a $\left.0,9 \mathrm{cmol} \mathrm{dm}^{-3}\right)$ para os solos avaliados nos sistemas agroflorestais. Seguindo esta classificação e comparando com resultados deste estudo, os valores encontrados apresentaram nível "médio" para a floresta secundária, roça 2 e pastagem e "baixo" para o restante dos 
tratamentos.

Ao determinar a concentração de magnésio em diferentes níveis de profundidade em solos sob sistemas agroflorestais no Município de Marituba-PA, Sena (2006) encontrou concentração variando de 0,46 $\mathrm{cmol}_{\mathrm{c}} \mathrm{dm}^{-3}(5-10 \mathrm{~cm})$ a $0,66 \mathrm{cmol}_{\mathrm{c}} \mathrm{dm}^{-3}(0-5 \mathrm{~cm})$ no período chuvoso, e de $0,17 \mathrm{cmol}_{\mathrm{c}} \mathrm{dm}^{-3}(10-20 \mathrm{~cm})$ a $0,32 \mathrm{cmol}_{\mathrm{c}} \mathrm{dm}^{-3}(0-5 \mathrm{~cm})$ no período seco, estes últimos considerados valores de nível "baixo", assemelhando-se com os resultados deste estudo que apresentou níveis "baixos" na concentração de magnésio para a maioria dos tratamentos. Quando analisados os solos sob diferentes sistemas de uso da terra, Sena (2006) verificou uma maior concentração de magnésio no SAF cacau + açaí $\left(0,64 \mathrm{cmol}_{\mathrm{c}} \mathrm{dm}^{-3}\right)$ e menor na floresta secundária $\left(0,56 \mathrm{cmol}_{\mathrm{c}} \cdot \mathrm{dm}^{-3}\right)$, no período chuvoso. No período seco, o autor registrou o maior valor de $0,27 \mathrm{cmol}_{\mathrm{c}} \mathrm{dm}^{-3}$ (pupunheira) e menor de $0,17 \mathrm{cmol}_{\mathrm{c}} \mathrm{dm}^{-3}$ (açaizeiro), valores estes, considerados de "baixo".

Ao avaliar solos sob sistemas agroflorestais, capoeira e pastagem no Município de Aurora do ParáPA, Rodrigues (2006) encontrou valores médios de concentração de magnésio entre $0,28 \mathrm{cmol}_{\mathrm{c}} \mathrm{dm}^{-3}$ (cedro) e $0,76 \mathrm{cmol}_{\mathrm{c}} \mathrm{dm}^{-3}$ (capoeira), no período seco. Já no período chuvoso, encontrou valores de $0,24 \mathrm{cmol}_{\mathrm{c}} \mathrm{dm}^{-3}$ (pastagem) e $0,62 \mathrm{cmol}_{\mathrm{c}} \mathrm{dm}^{-3}$ (capoeira). Em ambos os períodos os maiores valores para este macronutriente foram registrados no tratamento capoeira.

Os teores de potássio estão apresentaram menores valores para o SAF2 com $0,010 \mathrm{cmol}_{c} \mathrm{dm}^{-3}$ e o maior na Roça $1 \mathrm{com} 0,083 \mathrm{cmol}_{\mathrm{c}} \mathrm{dm}^{-3}$. O potássio por ser bastante móvel no solo é facilmente lixiviado em solos com baixa CTC como, por exemplo, em solos arenosos como os solos amazônicos. Seu teor no solo, considerado como "médio" é de 0,1 a 0,3 $\mathrm{cmol}_{\mathrm{c}} \mathrm{kg}^{-1}$. Portanto, neste estudo, as concentrações médias para este nutriente são consideradas "baixas". As cinzas são boas fontes de potássio, o que pode ter contribuído para o valor um pouco maior na Roça 1 que, em 2006 (após pousio) teve a área queimada para receber a mandioca.

O teor de potássio encontrada por Rodrigues (2006) em solo sob SAF, capoeira e pastagem, no Município de Aurora do Pará, no período seco, variaram de 0,02 $\mathrm{mg} \mathrm{dm}^{-3}$ (mogno + cedro e mogno + neen) a $0,14 \mathrm{mg} \mathrm{dm}^{-3}$ (pastagem), já no período chuvoso variou de $0,03 \mathrm{mg} \cdot \mathrm{dm}^{-3}$ (mogno + cedro) a $0,09 \mathrm{mg} \mathrm{dm}^{-3}$ (capoeira). Sena (2006) encontrou teores deste nutriente em solo em Marituba-PA, variando de 1,55 cmolc $\mathrm{dm}^{-3}(0-5 \mathrm{~cm})$ a $0,55 \mathrm{cmol}_{c} \mathrm{dm}^{-3}(10-20 \mathrm{~cm})$ no período chuvoso, e de $0,08 \mathrm{cmol}_{\mathrm{c}} \mathrm{dm}^{-3}(0-5 \mathrm{~cm})$ a $0,05 \mathrm{cmol}_{c}$ $\mathrm{dm}^{-3}(10-20 \mathrm{~cm})$ no período seco. Comparando os diferentes sistemas de uso do solo, este autor obteve resultados entre $1,98 \mathrm{cmol}_{c} \mathrm{dm}^{-3}$ (floresta secundária) e $0,39 \mathrm{cmol}_{\mathrm{c}} \mathrm{dm}^{-3}$ (açaizeiro) no período chuvoso, e em torno de $0,08 \mathrm{cmol}_{\mathrm{c}} \mathrm{dm}^{-3} \mathrm{em}$ todos os sistemas no período seco. Estes resultados são diferentes dos obtidos neste estudo, os quais tiveram suas amostras de solo coletadas no período seco (dezembro).

A ação microbiana do solo no processo de mineralização é intensificada no período chuvoso, liberando $\mathrm{K}$ contido na matéria orgânica para a solução do solo, o que pode justificar os maiores valores encontrados em coletas realizados no período com maior pluviosidade. Araújo et al. (2006) estudando a fertilidade de solos sob sistemas agroflorestais em Esperantina-TO, encontraram valores decrescentes para o potássio em função da profundidade do solo. No período chuvoso, as concentrações deste nutriente foram 
de $1,02,0,64$ e $0,35 \mathrm{mmol}_{\mathrm{c}} \mathrm{dm}^{-3}$ nas profundidades $0-10 \mathrm{~cm}, 0-20 \mathrm{~cm}$ e $20-40 \mathrm{~cm}$, respectivamente. E no período seco, os valores médios de $\mathrm{K}$ foram de $0,73,0,40$ e $0,19 \mathrm{mmol}_{\mathrm{c}} \mathrm{dm}^{-3}$ nas mesmas profundidades.

Ao comparar a fertilidade de solos sob sistemas agroflorestais e sob sistemas convencionais de uso da terra no Sudeste brasileiro, Perez et al. (2004) verificaram que os valores mais elevados de $\mathrm{pH}$, cátions trocáveis, CTC efetiva, CTC total, P e K, encontram-se principalmente na superfície, provavelmente associados aos seus maiores conteúdos de matéria orgânica. Aguiar et. al. (2006) ao quantificarem perda de solo, água e nutrientes por processos erosivos na região do semiárido, registraram que o potássio, em geral, apresentou uma perda total superior à do fósforo, por exemplo, que pode ter ocorrido devido a maior solubilidade do $\mathrm{K}$ em relação ao P, o que facilita seu transporte pela água e por seu maior teor no solo. Nóbrega et al. (2004) também verificaram uma queda significativa no nível de potássio disponível em um Planossolo solo após 55 meses da implantação de um sistema agroflorestal no Município de Seropédica-RJ.

Os valores da concentração de cálcio variaram de $3,38 \mathrm{cmol}_{c} \mathrm{dm}^{-3}$ no SAF1 a 5,65 $\mathrm{cmol}_{c} \mathrm{dm}^{-3}$ no SAF3. Teores de cálcio no solo entre 2,0 a 4,0 $\mathrm{cmol}_{\mathrm{c}} \mathrm{kg}^{-1}$ podem ser considerados como "médio" (SENGIK, 2005). 0 SAF3 foi o único tratamento que apresentou valor considerado "alto" para este macronutriente (Figura 8 e Tabela 2).

Em análise química realizada em solos com SAF, capoeira e pastagem, no município de Aurora do Pará, Rodrigues (2006) obteve resultados de concentração de cálcio variando de $0,33 \mathrm{mg} \mathrm{dm}^{-3}$ (capoeira) a $1,82 \mathrm{mg} \mathrm{dm}^{-3}$ (mogno + neen) no período seco. No período chuvoso, os valores variaram de 0,48 $\mathrm{mg} \mathrm{dm}^{-3}$ (pastagem) a 2,16 mg dm $\mathrm{m}^{-3}$ (capoeira). No Município de Marituba-PA, Sena (2006) encontrou teores de cálcio variando de $0,97 \mathrm{cmol}_{\mathrm{c}} \mathrm{dm}^{-3}(0-5 \mathrm{~cm})$ a $0,71 \mathrm{cmol}_{c} \mathrm{dm}^{-3}(10-20 \mathrm{~cm})$ no período chuvoso e de $0,43 \mathrm{cmol}_{\mathrm{c}} \mathrm{dm}$ ${ }^{3}(0-5 \mathrm{~cm})$ a $0,27 \mathrm{cmol}_{\mathrm{c}} \mathrm{dm}^{-3}(10-20 \mathrm{~cm})$ no período seco. Ao comparar os diferentes sistemas de uso, este mesmo autor registrou valores de $1,06 \mathrm{cmol}_{c} \mathrm{dm}^{-3}$ (cacau + açaí) a 0,59 $\mathrm{cmol}_{c} \mathrm{dm}^{-3}$ (cacau + pupunha) no período chuvoso, e de $0,27 \mathrm{cmol}_{c} \mathrm{dm}^{-3}$ (cacau + açaí) a $0,51 \mathrm{cmol}_{\mathrm{c}} \mathrm{dm}^{-3}$ (pupunha) no período seco. Estes resultados apresentados são considerados de nível "baixo", com valores inferiores aos encontrados neste estudo, portanto, considerados solos mais ácidos em suas amostras de coleta.

Nóbrega et al. (2004) registraram o melhor valor de cálcio no solo 24 meses após a implantação de um sistema agroflorestal no Sudeste brasileiro $\left(2,2 \mathrm{cmol} \mathrm{dm}^{-3}\right)$, caindo para $1,8 \mathrm{cmol} \mathrm{dm}^{-3}$ após 55 meses. Perez et al. (2004) verificou as maiores porcentagens de saturação de cálcio em sistemas agroflorestais que em sistemas convencionais, sugerindo uma melhor fertilidade do solo nestes primeiros.

\section{CONCLUSÕES}

Considerando os resultados apresentados na avaliação das propriedades químicas de solos sob sistemas agroflorestais, agricultura de corte e queima e pastagem em áreas de agricultores familiares em São Francisco do Pará, pode-se concluir que: a) os solos analisados, em geral, apresentaram baixo teor de nutrientes e elevada acidez, apesar de apresentarem teor médio de matéria orgânica; b) as queimas e adubações realizadas nas áreas podem causar diferenças significativas nos valores de algumas variáveis analisadas; c) com relação às áreas sob sistemas agroflorestais, os agricultores ainda utilizam baixo nível 
tecnológico.

\section{REFERÊNCIAS}

AMARAL, E. F.; MELO, A. W. F.; OLIVEIRA, T. K.. Levantamento de reconhecimento de baixa intensidade dos solos da região de inserção do Projeto RECA, Estados de Rondônia, Acre e Amazonas. Rio Branco: Embrapa Acre, 2000.

ARAÚJO, G. P.; COLLIER, L. S.. Parâmetros da fertilidade dos solos em sistemas agroflorestais em Esperantina-TO. 2006.

EMBRAPA. Manual de métodos de análise de solo. Rio de Janeiro: Embrapa, 1997.

FERNANDES, L. A.; SIQUEIRA, J. O.; GUEDES, G. A. A.; CURI, N.. Propriedades químicas e bioquímicas de solos sob vegetação de mata e campos cerrados adjacentes. Ciência e Agrotecnologia, v.21, n.1, p.58-70, 1997.

FERREIRA, C. P.. Atributos físicos-hídricos e químicos do solo em sistemas agrícolas na microrregião de CastanhalPA. Tese (Doutorado) - Universidade Federal Rural da Amazônia, Belém, 2004.

FRANCO, F. S.; COUTO, L.; CARVALHO, A. F.; JUCKSCH, I.; FERNANDES FILHO, E. I.; SILVA, E.; MEIRA NETO, J. A. A.. Quantificação de erosão em sistemas agroflorestais e convencionais na Zona da Mata em Minas Gerais. R. Árvore, Viçosa, v.26, n.6, p.751-760, 2002.

IAPAR. Instituto Agronômico do Paraná. Amostragem do solo para análise química: plantio direto e convencional, culturas perenes, várzeas, pastagens e capineiras. Londrina: IAPAR, 1996.

IDESP. Instituto de Desenvolvimento Econômico-Social do Pará. Síntese dos Municípios. Estudos Climáticos do Estado do Pará. IDESP, 1993.

IDESP. Instituto de Desenvolvimento Econômico-Social do Pará. Setor de Coleta e Tratamento de Dados. São Francisco do Pará: IDESP, 1995.

LEITE, J. B. V.; VIRGENS, A. C.. Sistemas agroflorestais no sudeste da Bahia: uma revisão conceitual. In: CONGRESSO BRASILEIRO DE SISTEMAS AGROFLORESTAIS, 4. Anais. Ilhéus: Embrapa, 2002.

MALAVOLTA, E.. Elementos de nutrição mineral de plantas. São Paulo: Agronômica Ceres, 1980.

MARIM, A. M. P.; MENEZES, R. S. C.; SILVA, E. D.; SAMPAIO, E. V. S. B.. Efeito da Gliricidia sepium sobre nutrientes do solo, microclima e produtividade do milho em sistema agroflorestal no agreste paraibano. Revista Brasileira Ciência do Solo, v.30, p.555-564, 2006.

NEVES, Y. P.; MARTINEZ, H. E. P.; SOUZA, C. M.; CECON, P. R.. Teor de água e fertilidade do solo com cafeeiros cultivados em sistemas agroflorestais. Revista Árvore, Viçosa, v.31, n.4, 2007.

NÓBREGA, P. O.; CAMPELLO, E. F. F.; SILVA, G. T. A.; RESENDE, A. S.. Agrofloresta em um sistema orgânico de produção. 2004.

OSAKI, F.. Calagem e adubação. Campinas: Instituto Brasileiro de Ensino Agrícola, 1991.

PEREZ, A. M. M.; JUCKSCH, I.; MENDONÇA, E. S.; COSTA, L. M.. Impactos da implementação de um sistema agroflorestal com café na qualidade do solo. Agropecuária Técnica, v.25, n.1, p.25-36, 2004

RAIJ, B. V.; CANTARELA, H.; QUAGGIO, J. A.; FURLANI, A. M. C.. Recomendações para adubação e calagem para o Estado de São Paulo. Campinas: Instituto Agronômico \& Fundação IAC, 1996.

RODRIGUES, R. C.. Biomassa microbiana e acúmulo de liteira em sistemas agroflorestais compostos por meliáceas utilizadas como indicadores biológicos de qualidade do solo. Tese (Doutorado) - Universidade Federal Rural da Amazônia, Belém, 2006.

SALGADO, B. G.; MACEDO, R. L. G.; ALVARENGA, M. I. N.; VENTURIN, N.. Avaliação da fertilidade dos solos em sistemas agroflorestais com cafeeiro (Coffea arabica L.) em Lavras-MG. Revista Árvore, Viçosa, v.30, n.3, p.343-349, 2006.

SENA, W. L.. Avaliação dos atributos químicos e carbono microbiano de um Latossolo Amarelo sob sistemas agroflorestais em comparação com a floresta secundária, Marituba, PA. Tese (Doutorado em Ciências Agrárias) Universidade Federal Rural da Amazônia, Belém, 2006.

SENGIK, E. S.. Os macronutrientes e os micronutrientes das plantas. 2005.

THEODORO, V. C. A.. Caracterização de sistemas de produção de café orgânico, em conversão e convencional. Dissertação (Mestrado em Fitotecnia) - Universidade Federal de Lavras, Lavras, 2001.

A CBPC - Companhia Brasileira de Produção Científica (CNPJ: 11.221.422/0001-03) detém os direitos materiais desta publicação. Os direitos referem-se à publicação do trabalho em qualquer parte do mundo, incluindo os direitos às renovações, expansões e disseminações da contribuição, bem como outros direitos subsidiários. Todos os trabalhos publicados eletronicamente poderão posteriormente ser publicados em coletâneas impressas sob coordenação da Sustenere Publishing, da Companhia Brasileira de Produção Científica e seus parceiros autorizados. Os (as) autores (as) preservam os direitos autorais, mas não têm permissão para a publicação da contribuição em outro meio, impresso ou digital, em português ou em tradução. 